\title{
THE OPTOMETRIC HISTORICAL SOCIETY
}

Protect and promote the historical legacy of the profession of optometry.

\section{THE ARCHIVES \& MUSEUM OF OPTOMETRY}

Collect, preserve, interpret and make available for research archival resources and museum objects that document the history of the profession of optometry as a clinical practice, academic discipline, and a health science.

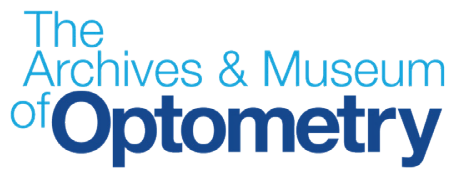

and

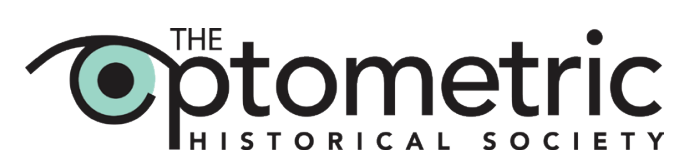

are Heritage Services programs of

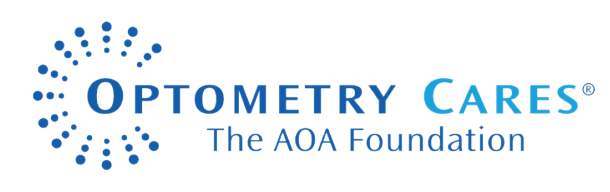

243 N. Lindbergh Blvd.

St. Louis, MO 63141

Toll Free: 800.365 .2219 , ext. 4200

Phone: 314.983 .4200 | Fax:

314.991.4101 foundation@aoa.org aoafoundation.org 